\title{
Accessibility to services of general interest in polycentric urban system planning: the case of Portugal
}

Teresa Sá Marques, Miguel Saraiva, Diogo Ribeiro, Ana Amante, Duarte Silva \& Paulo Melo

To cite this article: Teresa Sá Marques, Miguel Saraiva, Diogo Ribeiro, Ana Amante, Duarte Silva \& Paulo Melo (2019): Accessibility to services of general interest in polycentric urban system planning: the case of Portugal, European Planning Studies, DOI: 10.1080/09654313.2019.1658718

To link to this article: https://doi.org/10.1080/09654313.2019.1658718

曲 Published online: 04 Sep 2019.

Submit your article to this journal 전

Џ Article views: 86

Q View related articles ¿

View Crossmark data $[\pi$ 


\title{
Accessibility to services of general interest in polycentric urban system planning: the case of Portugal
}

\author{
Teresa Sá Marques (D) ${ }^{a}$, Miguel Saraiva (D) ${ }^{a}$, Diogo Ribeiro ${ }^{a}$, Ana Amante (1D ${ }^{a}$, \\ Duarte Silva ${ }^{b}$ and Paulo Melo ${ }^{c}$ \\ ${ }^{\mathrm{a} C E G O T}$ Research Centre, Faculty of Arts and Humanities of the University of Porto, Porto, Portugal; ${ }^{\mathrm{b}}$ Ministry \\ of Planning and Infrastructures, Lisbon, Portugal; 'Infrastructures of Portugal, Lisbon, Portugal
}

\begin{abstract}
Today, major planning agendas in Europe steer the future of territorial organization towards an urban polycentric perspective. The accessibility to services of general interest (SGI), a significant source of spatial inequality in Europe, is one of the key challenges to address. However, instruments needed to support the implementation and monitoring of territorial policy measures regarding the distribution of, and accessibility to SGI are still under-developed. Studies generally relate to the (intra)regional and not the national scale. When they do so, they lose local specificity as they often consider the existence/availability of services at a given scale and not the actual capacity to reach their (often just estimated) location through the transport network. In the context of the revision of Portugal's National Plan for Territorial Planning Policies, this paper presents a comprehensive multi-criteria location-based approach for measuring the factual accessibility to a representative range of SGI at the national Portuguese scale. Results are evaluated considering the dichotomy between centrality and periphery, high and low density, and the regional disparities found. High accessibility values do not necessarily mean greater territorial cohesion. Contributions to the development of national planning policies that respond to cohesion challenges are also debated.
\end{abstract}

\section{ARTICLE HISTORY}

Received 1 November 2018

Revised 9 August 2019

Accepted 16 August 2019

\section{KEYWORDS}

Accessibility; services of general interest; urban systems; polycentrism; territorial cohesion; social cohesion

\section{Introduction}

Today, the major European planning agendas such as the Territorial Agenda 2020 (EC, 2011b), the Pact of Amsterdam (EU, 2016), or programmes like ESPON (European Spatial Planning Observation Network) clearly steer the future of territorial organization towards an urban polycentric perspective. Urban systems have been called an hegemonic objective of the European policy (ESPON, 2016; Salvati \& De Rosa, 2014), and authors agree that they possess the potential to become the main drivers of EU's social, economic and territorial cohesion policy. This is because they can create critical economic mass and thus be better equipped to deal with the complexities of social-spatial interactions (Alexiadis, 2017; Burger, Meijers, \& van Oort, 2014; Cattan, 2007; Dühr, 2005; Hall,

CONTACT Miguel Saraiva miguelmsaraiva@gmail.com E CEGOT Research Centre, Faculty of Arts and Humanities of the University of Porto, Via Panorâmica s/n, 4150-564 Porto, Portugal 
2009; Marques, 2016; Schmitt, 2013). Furthermore, by increasing economic competitiveness, territorial cooperation, quality-of-life and levels of urban and regional development, they are fitted to reduce inter and intra-regional disparities (Burger, van der Knaap, \& Wall, 2014; Carmo, 2013; Marques, 2016; Salvati \& De Rosa, 2014).

Nonetheless, such a perspective has also been the object of critique. Authors consider that the concept itself does not possess a clear definition, and that its geo-political complexity hinders the creation of homogenous models at European scale (Burger, van der Knaap, et al., 2014; Dühr, 2005; Hoyler, Kloosterman, \& Sokol, 2008; Pain, 2007; Palma, Rauhut, \& Humer, 2015; Salvati \& De Rosa, 2014; Schmitt, 2013; Vandermotten, Halbert, Roelandts, \& Cornut, 2008).

One of the greatest challenges is the development of governance models suitable to functional regions rather than territorial jurisdictions (Brezzi \& Veneri, 2015; Burger \& Meijers, 2012; Burger, van der Knaap, et al., 2014; Gløersen, 2007; Groth \& Smidt-Jensen, 2007; Marques, 2016; Schmitt, 2013). Consequently, current research has moved from strict morphological analysis based on statistical indicators (such as those related to the size, hierarchy and distribution of urban centres) to more comprehensive functional approaches (Cattan, 2007; Dühr, 2005; Hall, 2009; Marques, 2016; Schmitt, 2013). These integrate the importance of each node in the network (i.e. the capacity to attract specific functions) to relational analysis. Such analyses uncover territorial patterns of economic and social interactions, based on network flows, connectivity and cooperation between territories and their agents. Precisely, ESPON's recent Policy Brief Report on Polycentric Territorial Structures and Territorial Cooperation (ESPON, 2016), declares that the pattern of urban systems at European scale should be based on three criteria; (i) the hierarchy of urban settlement structure, showing different size and functions of urban nodes; (ii) accessibility patterns, revealing the possibility for people to connect within the region, the country and the EU; and (iii) existing territorial cooperation structures and practices.

In this paper, we aim to give specific contributions to the understanding of the second criterion: accessibility patterns. In a wider logic of polycentric development as a catalyst for social and territorial cohesion policies (Evers, 2008; Faludi, 2007; Medeiros, 2016; Santinha \& Marques, 2012), we retake the problematic of the accessibility to basic and other services of general interest (SGI), such as those related to education, health or justice. Although they can be provided either by the state or the private sector, SGI are subject to specific public service obligations, namely to be accessible for all citizens in order to ensure their basic needs (EC, 2011a). Such a concern has long been withstanding in the literature, but recently it has evolved to encompass the cohesion debate (Fassmann, Rauhut, da Costa, \& Humer, 2015; Humer, 2014; Rauhut \& Ludlow, 2013). In the aftermath of the economic and financial crisis, accessibility to SGI should further be aligned with the social and territorial cohesion agenda (EC, 2011a). This is particularly so in regions where demographic and economic decline has led to an insufficient critical mass capable of sustaining a sufficient level of basic services (EC, 2007).

Indeed, insufficient access to SGI is still viewed as one of the most significant sources of spatial inequality in the European space (Malý, 2016). Or rather, there are still many disparities at regional level in their provision (Marques da Costa, Palma, \& Marques da Costa, 2015). However, although the importance of accessibility in European spatial development is widely acknowledged (Malý, 2016), instruments needed to support the implementation, monitoring and evaluation of territorial policy measures regarding the distribution of, and 
accessibility to services of general interest are still under-developed (Rauhut \& Ludlow, 2013). As Milbert, Breuer, Rosik, Stepniak, and Velasco (2013) note, neither the meaning of the term 'services of general interest' nor 'equality of access' have been clearly defined. Furthermore, most studies relating accessibility to territorial cohesion (see next section) calculate it at a regional or inter-regional scale, and consider the availability of services at a given scale (their provision) and not actually the physical capacity to reach them through transport networks. Data constraints also lead to the estimation, or generalization, of service location.

Today, many national planning systems around Europe are steadily implementing the polycentric perspective and aim to directly to respond to the EU cohesion guidelines. Consequently, more comprehensive mechanisms for measuring and evaluating the accessibility to SGI within countries or larger functional regions, rather than relying on regional estimations, need to be devised, tested and implemented. In this paper, such a methodology is proposed, considering Portugal as a case study and building on the work performed for the 2018 revision of the National Plan for Territorial Planning Policies (PNPOT). Using a complete georeferenced database of SGI of the various Portuguese Ministries, and the road network of the Infrastructures of Portugal, this paper aims to present a multi-criteria location-based approach for measuring and evaluating the accessibility to a representative range of SGI at the national scale.

In Section 2, we debate how accessibility to services has been used as an instrument for measuring and implementing cohesion policies in the EU. In Section 3, we look more closely to the Portuguese PNPOT and its strategic orientations for the provision of services. Then, in Sections 4 and 5, we trace the multi-criteria approach developed to determine and evaluate SGI accessibility. These results are set against an analysis of population and spatial coverage, leading to a discussion concerning the dichotomy between centrality and periphery, high and low density, and the regional disparities found. We finish by commenting on the overall contribution that these space-based processes have and should further have in the development of national planning policies in general, and in responding to cohesion challenges in particular.

\section{Accessibility to services as an instrument of cohesion}

\subsection{Measuring accessibility}

As defined by Litman (2003), accessibility represents the ability to reach desired goods, services and destinations (the 'opportunities'). In this sense, accessibility can be seen as the ultimate goal of most transportation, with improved access benefiting society in general (Bertolini, le Clercq, \& Kapoen, 2005). Indeed, both the Europe 2020 Strategy and the Territorial Agenda 2020 consider the improvement of overall accessibility in the European space as a main driver of the proposed goals of smart, sustainable and inclusive growth (Zaucha, Komornicki, Böhme, Świątek, \& Żuber, 2014). The operationalization of accessibility based on accessibility measures further enables the integration of land-use and transport systems as part of strategic policies (Hull, Silva, \& Bertolini, 2012; Silva, Bertolini, te Brömmelstroet, Milakis, \& Papa, 2017).

There are, however, different groups of accessibility measures as well as a wide range of methodological approaches used in planning practice (Baradaran \& Ramjerdi, 2001; Bhat 
et al., 2000; Cerdá, 2009; El-Geneidy \& Levinson, 2006; Geurs \& van Eck, 2001; Handy \& Niemeier, 1997; Hägerstraand, 1970; Koenig, 1980; Scheurer \& Curtis, 2007). The detailed description of these measures falls out of the range of this paper; but in a very succinct way, following Geurs and van Wee (2004), it can be said that the measurement of accessibility is focused on one or more of four components. The land-use component reflects the land use system and the spatial distribution of opportunities. The transport component describes the transport system and travel demand. The individual component describes the characteristics of individuals and their needs and choices. And the temporal component reflects the time constraints and the availability of opportunities. An additional component, information, has since been proposed, describing people's access to opportunities through virtual space and Information and Communication Technologies (Van Wee, Geurs, \& Chorus, 2013).

Moreover, accessibility measures are identified under, at least, one of four basic perspectives, associated to infrastructure-, location-, person- and utility-based measures (Amante, 2017; Hull et al., 2012). Infrastructure-based measures, also known as connectivity measures, deal with the performance of the transport system, and are generally based on distance (or travel time or average speed) (Geurs \& van Eck, 2001). Although they do not consider land use patterns and the spatial distribution of opportunities, the authors believe they should not be excluded from the measuring of accessibility.

Location-based measures have been calculated in various ways depending on the range of the analysis, and include several groups such as contour or cumulative-opportunities, potential and competition factors measures of spatial interaction models (Geurs \& van Wee, 2004; Miller, 2018). Contour measures, also known as cumulative opportunities or isochrones, display a given travel time, distance or cost to access one or various destinations (Geurs \& van Wee, 2004). Generally, they do not use an impedance function to weigh opportunities according to their attractiveness. Potential measures or Gravity model (Bhat et al., 2000; Hansen, 1959) are considered more accurate than contour measures despite being less easily interpreted. They are derived by weighting the opportunities in an area by measure of attraction (depending on their size or importance, for example) and using negative exponential, potential or log-logistic functions of distance or time travel (Handy \& Niemeier, 1997; Vale, Saraiva, \& Pereira, 2016). Potential accessibility measures have been used to evaluate the impacts of transport policy plans and land use (potential opportunities) in which no competition effects occur. Nevertheless, if they do occur, competition factors measures are used (Bhat et al., 2000; Geurs \& van Eck, 2001). Generally, the (inverse) balancing factor is considered a methodologically sound measure for analysing job accessibility, incorporating transport, land-use, temporal and individual components, as well as competition effects (Geurs \& van Eck, 2001).

Person-based measures are well-suited to analyse the impacts of land-use transportation scenarios and incorporate time-constraints at individual or household level. Hence, they are used to measure potential impacts of policies on different groups and social exclusion (Geurs \& van Wee, 2004). Finally, utility-based measures may be used for analysing economic impacts of accessibility scenarios (Baradaran \& Ramjerdi, 2001; Bhat et al., 2000; Geurs \& van Eck, 2001).

Authors agree that there is complexity in operationalizing such a range of measures in practice (Geurs \& van Eck, 2001; Geurs \& van Wee, 2004; Geurs, Boon, \& Van Wee, 2009). Furthermore, theoretical measures such as those pertaining to Competition Factors, 
Inverse balancing factors, person- and utility-based measures, are harder to interpret due to data collection constraints and the complexity of the models. Thus, authors have not yet agreed on the best way to operationalize accessibility. Consequently, the use of simpler accessibility measures is often defended (Brömmelstroet \& Bertolini, 2011; Makrí, 2001; Straatemeier, Bertolini, te Brömmelstroet, \& Hoetjes, 2010; Vandenbulcke, Steenberghen, $\&$ Thomas, 2009). According to Zaucha et al. (2014) managing accessibility as an instrument to improve quality of life and sustainable development is to balance the complex territorial arrangements that derive from such elements as the characteristics of the network infrastructure (for example, the number of possible connections between nodes or the average speeds of travel), the characteristics of the destinations, and how these are provisioned.

\subsection{Cohesion policy and SGI provision}

Through the cohesion policy instruments, a substantial amount of European public funding has been dedicated to increasing accessibility in peripheral and/or landlocked regions. Regional investment programmes have included considerable funding for transport infrastructure improvements, as a more straightforward solution to the accessibility problem. Indeed, recent studies have employed sophisticated accessibility measures and inequality indicators to assess whether transport infrastructure improvements have the intended effect of decreasing disparities among European regions (Jacobs-Crisioni et al., 2016). However, their results have been varied, depending on the transport mode analysed. For example, road link upgrades generally improve territorial cohesion whilst high speed railway links accentuate differences in accessibility between regions. The same results had previously been reached by López, Gutiérrez, and Gómez (2008), with the authors also stressing the influence of scale. A new infrastructure connecting a peripheral Member State to the EU core may increase cohesion, whereas the same infrastructure may have polarizing effects at national or regional level. The recent study of Stepniak and Rosik (2016) in Poland also did not show a positive affinity between cohesion and the improvement in accessibility resulting from transport investment.

On the other hand, location-based studies have extensively reflected on SGI provision. This is because SGI accessibility can be used as a proxy for quality of life and cohesion (López et al., 2008). As well, SGI are deemed instrumental in the promotion of longrun growth (for example regarding education), or inclusive growth (for example, regarding social care) (Zaucha et al., 2014). Hence, the authors consider that territorial cohesion is not achieved so long as insufficient access to SGI remains. In fact, in a recent study conducted in Colombia, Sánchez-Zamora, Gallardo-Cobos, and Romero-Huertas (2017) found that a composite variable relating to access to services, social inclusion and development had the greatest correlation with territorial cohesion. Composite variables such as population flows, connectivity and connection; and Employment, innovation and economic diversification, correlated less. This contrasts with a previous study by Borges and Johansson (2012), which concluded that there was no relationship between the provision of SGI and polycentrism. However, polycentrism is itself a complex and non-consensual concept (Carmo, 2013; Hoyler et al., 2008; Pain, 2007; Schmitt, 2013; Vandermotten, Roelandts, \& Cornut, 2007), that has often been measured by assumed morphological 
approaches (Brezzi \& Veneri, 2015). Consequently, according to Palma et al. (2015), polycentrism may not be considered as a driver as such of SGI provision, but should definitely be regarded as an influencing factor.

In theory, the polycentric configuration results in a more equitable spatial distribution across the territory, whist also allowing for a greater sustainability of services based on the market. This is more achievable if the population of peripheral areas is significant enough to ensure service provision, unlike what is expected in peripheral territories in a monocentric urban system (Borges \& Johansson, 2012; Malý, 2016; Palma et al., 2015). Analysing the NUT2 regions of Europe, Humer and Palma (2013) concluded that settlement patterns, population density and economic prosperity had a much greater correlation with the provision of SGI than demographic and societal indicators. The following year, Humer (2014) re-defined the four most important drivers for SGI provision: demography, society, economy and environment. Demography shapes the demand side; societal values impact on policy options; and macro and micro economic potentials set the limits of service provision in financial respects.

According to Jacobs-Crisioni et al. (2016), differences in local population levels have a limited impact on average accessibility levels, but have a large impact on territorial inequalities related to accessibility. A presence of a large conurbation generally guarantees better accessibility to specific functions (services and jobs). However, the more polycentric a region is, generally the fewer amenities exist. Thus, different locations require different accessibility standards for SGI, in terms of degrees of specialization and outreach. Services like kindergartens are rather universal, whilst hospitals or tertiary educational facilities should appear in poles of medium to higher centrality. Similar results have been reached in a recent paper by Kompil, Jacobs-Crisioni, Dijkstra, and Lavalle (2019), where the spatial distribution of services is simulated throughout Europe. Local services are generally expected to be easily accessible, though they take longer to reach in suburban and especially rural areas; whereas the average distance is expected to be greater for sub-regional services and greater still for regional services. Precisely analysing variables as number of kindergartens and hospital beds in a set of EU countries, Palma et al. (2015) perceive an impact of polycentricism on a national level in the provision of low and medium centrality services. No impact was found regarding high centrality services, perhaps because these are well provided in urban regions, but poor in rural regions. According to Kompil et al. (2019), metropolitan regions perform almost three times better than non-metropolitan regions in terms of accessibility to generic services.

As Soja (2010) or Malý (2016) discuss, it is practically impossible, due to financial, logistical and territorial constraints, to achieve an equal access to SGI. Therefore, a certain level of distributional inequality is inevitable. The acceptable level of this inequality is still under question (ESPON, 2013), but the previously cited authors agree that adequate and fair access in disadvantaged regions can be improved by more conscientious approaches, considering the multifaceted nature of urban systems. This means taking into account the territorial dimension, and the integration with other policies such as transport, social or e-policies, both at EU and national scales. According to Palma et al. (2015) polycentricism may actually not be creating more SGI in statistical terms, but it may allow for their more efficient production and distribution. 


\subsection{Applications in Europe}

Urban, metropolitan and regional studies focused on determining accessibility levels often consider the ability to reach one or more services of general interest. For example, studies applying location-based measures have considered distances to the closest health services (Apparicio, Abdelmajid, Riva, \& Shearmur, 2008), daycare facilities (Páez, Scott, \& Morency, 2012) or food retailers (Apparicio, Cloutier, \& Shearmur, 2007; Sadler, Gilliland, $\&$ Arku, 2011). Other studies have also analysed the amount of basic services for shops, schools, health care or employment within given travel impedance thresholds (Iacono, Krizek, \& El-Geneidy, 2010; Silva \& Pinho, 2010; Straatemeier \& Bertolini, 2008; Vale, 2010; Vasconcelos \& Farias, 2012).

At EU level, accessibility to SGI has been used as a measure of the disparities among countries or regions. Some studies have used a set of statistical indicators such as number of hospital beds or share of students (Marques da Costa, Palma, \& Marques da Costa, 2015; Palma et al., 2015) as a proxy for accessibility to SGI. Others, like the studies of Malý (2016) and Stepniak and Rosik (2016), in, respectively, a region of the Czech Republic and in Poland, have applied location-based measures. In the first case, the distance measured is to the localities (not the service themselves), for which the quantitative significance of each service has been previously obtained. In the second case, which uses a potential measure, population is used as a proxy for destination attractiveness.

Various ESPON studies have also approached this subject. Milbert et al. (2013) shows the results of the project indicators and perspectives for services of general interest in territorial cohesion and development (2010-2013). Here, distance-to-nearest-provider was individually calculated for eight SGI in five European regions in Austria, Germany, Hungary, Poland and Spain. The calculation was based on shortest travel time and considering a $1 \mathrm{~km}$ raster grid. Pharmacies and primary schools were considered as low centrality services; railway stations, hospitals and secondary schools were considered as medium centrality services; and airports, highway entrances and facilities of tertiary education were considered as high centrality services. Comparison with the distribution of population allows the identification of areas of high density of population and low accessibility to services.

The TRAAC project, TRansport ACCessibility at regional/local scale and patterns in Europe (2010-2012), aimed to extend the range and the spatial resolution of accessibility indicators and to explore the likely impact of policies to improve global, European and regional accessibility (Biosca, Spiekermann, \& Stępniak, 2013). Among other indicators, the study calculated travel time to the nearest hospital, the number of upper secondary schools within $30 \mathrm{~min}$ ' travel time (both contour measures), and the potential accessibility to basic health care. All calculations were made both for car travel and public transport. Case studies included regions in Spain, France, Italy, Germany, as well the entire countries of the Czech Republic, Poland, the Baltic States and Finland.

The INTERCO project focused on producing Indicators for Territorial Cohesion (Dao, Plagnat Cantoreggi, \& Rousseaux, 2017). It included potential accessibility-related variables such as access to schools, universities, hospitals or grocery services by road, rail and air modes. In its wake, the PROFECY project (Processes, Features and Cycles of Inner Peripheries in Europe) (ESPON, 2017) has produced several maps at an European scale for the potential accessibility by road, rail, air and multimodal. It also computed 
several types of location-based measures (for example travel times by car and availability within $15 \mathrm{~min}$ ) associated to nine services: banks, cinemas, doctors, hospitals, pharmacies, primary and secondary schools, supermarkets and convenience stores. The road networks and the location of the services were obtained via Open Street Maps.

Finally, EU's Territorial Modelling Platform LUISA (https://ec.europa.eu/jrc/en/luisa) contains information at regional level on access to local and regional services such as schools, health facilities or childcare services. It is based on average (road) distance per person to the nearest (generic and simulated) local facility, serving ideally 5-10 thousand people within a $5 \mathrm{~km}$ range. Its computation is set on a grid based on the population distribution from Geostat, dated from 2011, and a road network dated from 2014.

\section{Portugal's National Plan for Territorial Planning Policies (PNPOT) and the provision of services}

The case study of this research is Portugal. Portugal is a country of about 10 million inhabitants and 89 thousand square kilometres of area (INE, 2018). It is divided, in the mainland, into six NUTS 2: North, Centre, West and Tagus Valley, Lisbon, Alentejo and Algarve. The most important planning document in the country is the National Plan for Territorial Planning Policies (PNPOT). It stemmed from the coherent system defined by the Portuguese Basic Law on Spatial Planning Policy and Urbanism initially approved in 1998 (updated in 2014; Law $\mathrm{n}^{\circ}$ 31/2014 of May 30th), that also entailed lower-level regional (PROT), and municipal (PMOT) plans (Ferrão \& Mourato, 2010). The PNPOT version officially implemented in 2007 (Law n ${ }^{\circ}$ 58/2007 of September 4th), which was revised in 2018, introduced the first major national approach to urban polycentrism. Among other strategic objectives, it aimed to promote a harmonious urban system that would support a territorial organization oriented towards cohesion and an integrated and competitive economy. It proposed an urban system model supported on four major urban structures of greater density, aided by a set of polarities and urban axes located in territories of lower density.

In the following years, from 2008 to 2011, the various Regional Land Management Plans (PROT) were written or revised, assuming a crucial role in carrying out the development agenda of Portugal and supporting the creation of a system of integration and territorial cohesion. They translated the PNPOT guidelines into different polycentric urban models (one for each region), something which demonstrated the multifaceted and multiscaler character of the concept.

The revision of the PNPOT, approved in July 2018, aims, according to Resolution n. ${ }^{\circ}$ $44 / 2016$ of the Council of Ministers, to further promote the territorial dimension of the public policies at various scales, by reinforcing the contribute of the urban structure and the improvement of the quality of life in the country's development. Furthermore, it is intent on promoting territorial cohesion through a strategy supported on the development of wealth and jobs outside the major coastal metropolis by potentiating endogenous resources. This process, which the Resolution terms 'affirmation of the interior', is deemed a key factor in the economic development and territorial cohesion strategy of the country. Therefore, according to the same Resolution, the planning of infrastructural networks, facilities and public services of general interest should be based on the principles 
of territorial equity and efficiency, supported by the national urban system; thus promoting integrated and spatially balanced solutions for urban functions.

Particularly over the 1990s and the 2000s, the networks of facilities witnessed a considerable development, stemming from increasing social concerns but also from the steady financial support from the EU and the central administration. In the 2000s Portugal was one of the countries in Europe presenting higher SGI expenditures as shares of the GDP (Marques da Costa et al., 2015). Nonetheless, it is recognized that there are still territorial disparities in the availability and quality of services, and social disparities in the access to them. At the same time, inter-sectoral articulation needs to be promoted and new models for the provision of services need to be devised. There is therefore a need in Portugal, in the context of the revision of the PNPOT, for research that can quantify and evaluate the current provision of services and signal the want of specific territories, in order to contribute important guidelines to the cohesion policy agenda.

\section{Methodology}

Following the literature review, the purpose of this research is first to build an accessibility score to a representative range of SGI at national scale, based on a multi-criteria locationbased approach and up-to-date georeferenced information. Second, to measure and evaluate this accessibility in Portugal, so as to discuss spatial and population inequalities, thus informing upcoming cohesion policies within the context of the National Plan for Territorial Planning Policies (PNPOT).

In this research, the measurement of accessibility has been based on both transport and land-use components, as defined by Geurs and van Eck (2001) and Geurs and van Wee (2004). Both infrastructure-based (average travel speed) and location-based measures (namely cumulative-opportunities) have been used, supported by isochrones (representing opportunities' catchment areas). In a first stage we have computed three comprehensive accessibility indicators, derived from location and infrastructure-based measures, to get a sense of Portugal's overall accessibility patterns. Then we have calculated a more straightforward location-based measure for a more in-depth approach. Following previous ESPON studies, a motorised mode (car) was selected, considering different travel time thresholds.

Eight services (including both public and private establishments) have been selected, in order to cover different categories defined by the European Commission (2011a), and different centrality levels, as defined by Milbert et al. (2013). Pharmacies, kindergartens, basic schools and health centres were considered as basic services; courts and high schools as medium services; and hospitals and higher education (including Universities and Polytechnic Institutes) as high services. These services have previously been used in accessibility measures in other studies (Biosca et al., 2013; ESPON, 2017; Milbert et al., 2013).

The analysis has been performed at national scale, as previously done in some countries (Biosca et al., 2013), but with the distinction that complete official data has been used both for the location of services and the road network. This is an improvement from previous studies which have used estimations regarding the location of SGI or open data. As previously mentioned, the georeferenced database of SGI belongs to the various Portuguese Ministries responsible for each service category. Subsequently, it was compiled and 
verified by the project team. The road network belongs to the Infrastructures of Portugal, a public company under the tutelage of the Ministry of Planning and Infrastructure and the Ministry of Finance. The extension Network Analyst in ArcGIS was used to perform the various accessibility calculations.

A trio of accessibility indicators was initially calculated to evaluate the country's overall accessibility:

(i) Geographical Accessibility, which represents the relative centrality of each municipality considering the distribution of the population across the country (Equation (1)):

$$
A G_{i}=\sum_{j} \frac{P_{j}}{t_{i, j} \cdot S}
$$

where $A G_{i}$ is the Geographical Accessibility of municipality $i ; P_{j}$ the population living in municipality $j ; t_{i, j}$ the travel time between municipalities $i$ and $j$ in minutes; and $S$ a scale coefficient to guarantee an average mean of 100;

(ii) Index of Sinuosity, measuring the linearity in the road accessibility to the different municipalities, pondered by the population (Equation (2)):

$$
I S_{i}=\frac{\sum_{j} \frac{d r_{i, j}}{d_{i, j}} \cdot P_{j} \cdot e^{-\beta \cdot d r_{i, j}}}{\sum_{j} \cdot P_{j} \cdot e^{-\beta \cdot d r_{i, j}}}
$$

where $I S_{i}$ is the Index of Sinuosity of municipality $i(\%) ; P_{j}$ the population living in municipality $j ; d r_{i, j}$ the straight-line distance between municipalities $i$ and $j(\mathrm{~km}) ; d_{i, j}$ the fastest route distance through the road network between municipalities $i$ and $j$ $(\mathrm{km})$; and $\beta_{i, j}$ the impedance coefficient;

(iii) Infrastructural Accessibility, measuring the performance of the network to different territories, through the average equivalent straight-line speed in the accesses (in $\mathrm{km} /$ h) (Equation (3)):

$$
A I_{i}=\frac{\sum_{j} \frac{d r_{i, j}}{t_{i, j}} \cdot P_{j} \cdot e^{-\beta \cdot d r_{i, j}}}{\sum_{j} P_{j} \cdot e^{-\beta \cdot d r_{i, j}}}
$$

where $A I_{i}$ is the Infrastructural Accessibility of municipality $I(\mathrm{~km} / \mathrm{h}) ; P_{j}$ the population living in municipality $j$; $d r_{i, j}$ the straight-line distance between municipalities $i$ and $j(\mathrm{~km}) ; t_{i, j}$ the travel time between municipalities $i$ an $j$ in minutes; and $\beta_{i, j}$ the impedance coefficient.

In a second stage, the accessibility to the various services was computed based on isochrones maps; service areas at $5 \mathrm{~min}$ intervals from each service until $30 \mathrm{~min}$, and then at 10 min intervals until one hour. The accessibility to services does not exceed 60 min (even for higher centrality services) and the major fluctuations occur within the first half an hour. Hence smaller temporal intervals allow for a sufficiently detailed analysis. Only the map for pharmacies was calculated with different intervals due to the large number 
of existing facilities, when compared to other services considered in this research. In this case, the isochrones were computed at $5 \mathrm{~min}$ intervals until $15 \mathrm{~min}$, and then at $15 \mathrm{~min}$ intervals. With this exception, using the same thresholds for all services allows for direct comparisons of values, and visual comparisons between maps (that have the same scale).

Road speeds correspond to average running speeds, respecting the legal limits for the major road types in Portugal: $120 \mathrm{~km} / \mathrm{h}$ on freeways; $100 \mathrm{~km} / \mathrm{h}$ on express ways; $90 \mathrm{~km} /$ $\mathrm{h}$ on national roads; $70 \mathrm{~km} / \mathrm{h}$ on regional roads; $40 \mathrm{~km} / \mathrm{h}$ on connecting branches; and $60 \mathrm{~km} / \mathrm{h}$ on the remaining network.

The resulting isochrones for each type of service were then segmented by statistical subsections, considering the divisions of the National Statistics Institute and the population distribution. The main outcome of this step was the number of inhabitants with access to each service in a given time frame.

Eight nation-scale isochrones maps were thus produced, one for each service type. Then, the overall accessibility score was calculated using a simplified Multiple Criteria Decision Analysis method. As a first iteration, all variables were deemed as having the same weight. Not only this allows testing the model, it also derives from the literature and having selected, in this case, the simplest accessibility measures based on service location and travel time through the road network. Such measures do not take into account competition effects nor individualś perceptions nor preferences, as discussed by Geurs and van Wee (2004). Moreover, contour or cumulative-opportunity measures consider that all services are equally desirable, unrelatedly of travel time or type of service.

A SAW (Simple Additive Weighting) method for multi-criteria evaluation was used (Ginevičius, 2008), relying on a maximizing criteria normalization for each map (Equation (4)). Travel times were normalized on a scale [0-100]. Then all the isochrones maps were intersected, and the normalized scores for each resulting polygon added, considering their respective weight (in this case the same). Lastly, the obtained values were pondered by the area of the polygon, resulting in the final accessibility score.

$$
A_{j}=\left(\sum_{i} w_{i} a_{i j}\right) p_{i}
$$

where $A_{j}$ is the overall accessibility score for the polygon $j ; w_{i}$ is the weight of the service of general interest $i$; $\mathrm{a}_{i j}$ is the normalized accessibility value of each polygon $j$ for the service of general interest $i$; and $p_{i}$ is the ponderation based on the area of the polygon.

Calculations have been made for the entire country, and for high population density and low population density areas. These areas in Portugal have been institutionally defined according to a 2016 decision of the Interministerial Commission of Coordination, and can be consulted in the Official Administrative Letter of Portugal (CAOP) of that year.

\section{Results and discussion}

\subsection{Portugal's overall accessibility}

The national distribution of the three overall accessibility indicators: Geographical Accessibility, Index of Sinuosity, and Infrastructural Accessibility can be seen in Figure 1. 

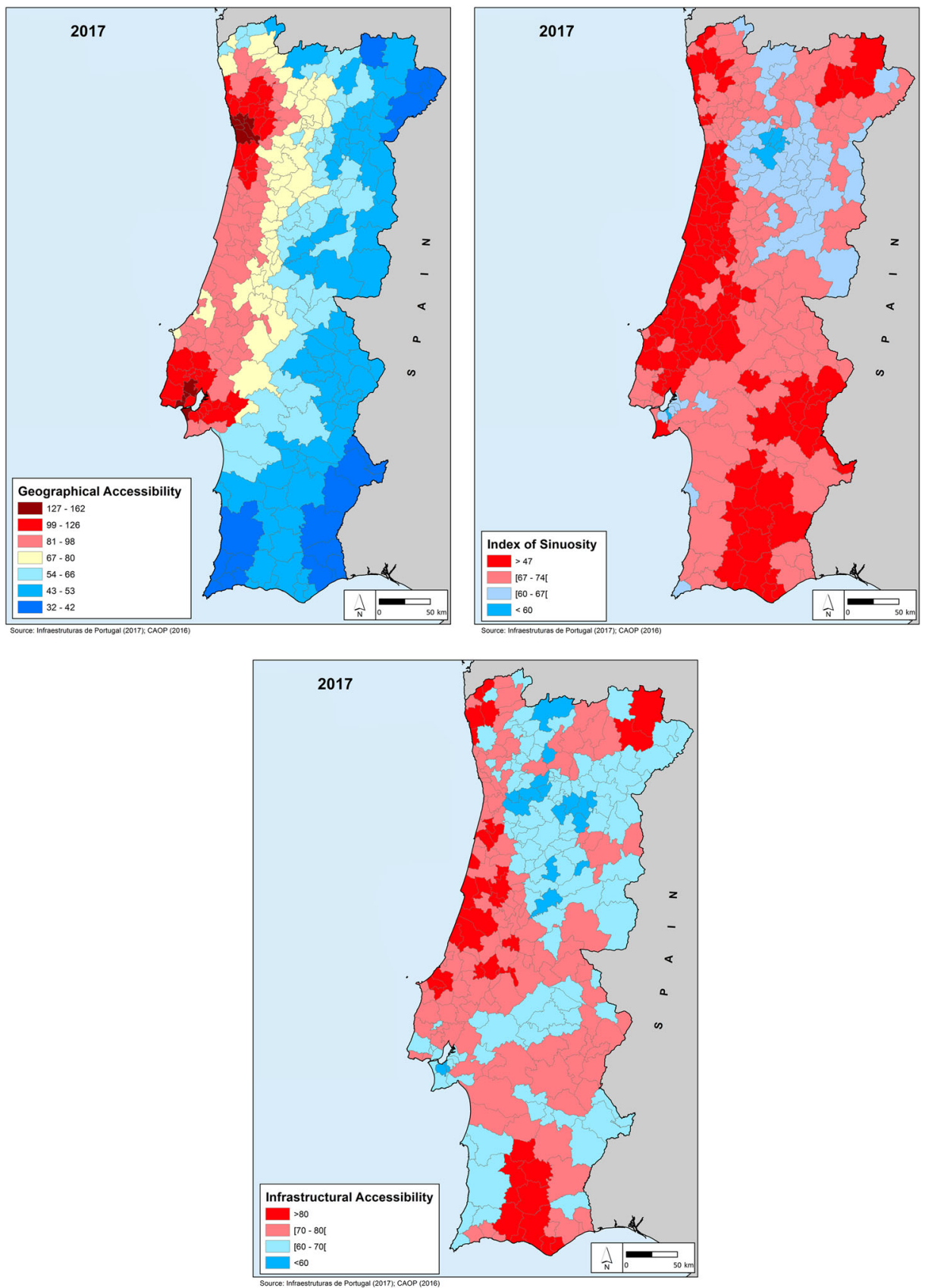

Figure 1. Geographical Accessibility, Index of Sinuosity and Infrastructural Accessibility in Portugal for 2017 (source: authors).

It is perceptible that, in terms of Geographical Accessibility, there are clearly two distinct realities in Portugal. Western Portugal, encompassing the metropolitan areas of Lisbon and Porto and the seaside territory between them, is characterized by a high degree of accessibility, particularly in the two main cities. On the other hand, eastern, 
inland and southern Portugal have increasingly lower degrees of segregation in terms of accessibility. The southern region of Algarve is clearly the region with the lowest geographical accessibility.

The Index of Sinuosity is relatively high throughout the country, which is in great part a result of a relatively high degree of Infrastructural Accessibility, particularly in the connection between Porto and Lisbon, and Lisbon and the Algarve. These high indicators are partly a consequence of the massive investment in road infrastructure that occurred in Portugal, particularly in the 1990s and the 2000s, stimulated by European funding. The Northern Interior region of Portugal stands out as having both the lowest Index of Sinuosity and Infrastructural Accessibility. Not only is this one of the most isolated regions in the country, it also encompasses several mountainous regions which generate added constraints for the creation of straight-line accessibilities.

\subsection{Portugal's accessibility to each service of general interest}

As Table 1 (for individual values) and Figures 2 and 3 (for cumulative values) display, there is a significant degree of accessibility of the country's population to basic services. In less than $5 \mathrm{~min}$, over $93 \%$ and over $95 \%$ of the population can reach a Pharmacy and a Basic School, respectively. In both cases, the number rises to $99 \%$ if we consider an under 10 min' time frame. Health centres, Kindergartens and High Schools have a similar distribution, being reachable by around $80 \%$ of the Portuguese population in under $5 \mathrm{~min}$ and $95 \%$ of the population in under $10 \mathrm{~min}$. Courts have a lower degree of accessibility at $5 \mathrm{~min}(60 \%)$ but are still reachable by $90 \%$ of the population in under $10 \mathrm{~min}$.

The higher order services considered, Higher Education and Hospitals, are understandably only reachable by less than half of the country's population under $5 \mathrm{~min}$, and around $70 \%$ in $10 \mathrm{~min}$. It takes another $5 \mathrm{~min}$, until $15 \mathrm{~min}$, for the reachable population to be close to $85 \%$ in both cases. There is hardly anyone who is more than 20 min away from a basic service, nor $40 \mathrm{~min}$ from a Hospital. However, around 1,5\% of the country's population needs a longer time than that to reach a higher education facility.

This high degree of accessibility does not mean, however, that there is an equitable distribution of services across the territory. The poles of concentration are geographically askew, as the various images of Figure 4 display. Even though $96 \%$ of the population have access to Basic Schools in less than $5 \mathrm{~min}$, this corresponds only to half of the country's area (Table 1 and Figure 2). It takes 10 min longer to reach $96 \%$ of the country's area. A similar scenario is seen for Pharmacies and Kindergartens. In $5 \mathrm{~min}$, only $30 \%$ of the country's area is reachable, and it takes $15 \mathrm{~min}$ (for Pharmacies) and $20 \mathrm{~min}$ (for Kindergartens) of travel time to encompass $90 \%$ of the country's area. For High Schools and Courts, $15 \%$ of the country is reachable in $5 \mathrm{~min}$ and $90 \%$ in $20 \mathrm{~min}$. Health Centres stand in between, with $21 \%$ for $5 \mathrm{~min}$ and $92 \%$ for $20 \mathrm{~min}$. For the high order services, only $5 \%$ of the country's area is within a distance of $5 \mathrm{~min}$. It takes until half an hour to encompass $83 \%$ of the country for Hospitals, and around $68 \%$ for Higher Education facilities.

These analyses also show that, for this particular case of Portugal, Health Centres and Kindergartens, initially assumed as low centrality services, actually have a behaviour closer to middle centrality services. 
Table 1. Percentage of the area and population that can reach services of general interest by travel time through the road network; overall and divided into high density and low density areas (source: authors).

\begin{tabular}{|c|c|c|c|c|c|c|c|c|c|c|c|c|c|c|c|c|}
\hline \multirow[b]{2}{*}{$\begin{array}{l}\text { Interval } \\
\text { (min) }\end{array}$} & \multicolumn{2}{|c|}{ Basic school } & \multicolumn{2}{|c|}{ Pharmacies } & \multicolumn{2}{|c|}{ Health centres } & \multicolumn{2}{|c|}{ Kindergarten } & \multicolumn{2}{|c|}{ High school } & \multicolumn{2}{|c|}{ Courts } & \multicolumn{2}{|c|}{ Higher education } & \multicolumn{2}{|c|}{ Hospital } \\
\hline & $\begin{array}{c}\% \\
\text { Area }\end{array}$ & $\begin{array}{c}\% \\
\text { Population } \\
\end{array}$ & $\begin{array}{c}\% \\
\text { Area }\end{array}$ & $\begin{array}{c}\% \\
\text { Population } \\
\end{array}$ & $\begin{array}{c}\% \\
\text { Area }\end{array}$ & $\begin{array}{c}\% \\
\text { Population }\end{array}$ & $\begin{array}{c}\% \\
\text { Area }\end{array}$ & $\begin{array}{c}\% \\
\text { Population } \\
\end{array}$ & $\begin{array}{c}\% \\
\text { Area }\end{array}$ & $\begin{array}{c}\% \\
\text { Population } \\
\end{array}$ & $\begin{array}{c}\% \\
\text { Area } \\
\end{array}$ & $\begin{array}{c}\% \\
\text { Population }\end{array}$ & $\begin{array}{c}\% \\
\text { Area } \\
\end{array}$ & $\begin{array}{c}\% \\
\text { Population }\end{array}$ & $\begin{array}{c}\% \\
\text { Area }\end{array}$ & $\begin{array}{c}\% \\
\text { Population }\end{array}$ \\
\hline \multicolumn{17}{|l|}{ Portugal } \\
\hline $5-10 \min$ & 35.9 & 3.1 & 35.2 & 5.4 & 33.1 & 12.1 & 31.0 & 15.0 & 30.8 & 17.0 & 30.0 & 31.6 & 10.7 & 21.4 & 14.0 & 28.0 \\
\hline $10-15 \mathrm{~min}$ & 12.7 & 0.6 & 18.5 & 1.3 & 25.0 & 3.4 & 18.3 & 2.0 & 24.9 & 4.0 & 27.0 & 7.0 & 13.5 & 13.2 & 18.0 & 13.0 \\
\hline $15-20 \mathrm{~min}$ & 2.8 & 0.1 & 9.6 & 0.0 & 12.7 & 1.0 & 10.6 & 2.0 & 15.4 & 1.0 & 17.0 & 1.9 & 14.1 & 7.5 & 18.0 & 7.0 \\
\hline $20-25 \min$ & 0.5 & 0.0 & & & 5.4 & 0.3 & 5.2 & 0.0 & 8.2 & 1.0 & 9.0 & 0.6 & 13.3 & 4.7 & 15.0 & 3.0 \\
\hline $25-30 \mathrm{~min}$ & 0.1 & 0.0 & & & 2.0 & 0.1 & 3.0 & 0.0 & 3.3 & 0.0 & 4.0 & 0.1 & 11.4 & 2.7 & 13.0 & 2.0 \\
\hline $30-40 \mathrm{~min}$ & 0.0 & 0.0 & 0.1 & 0.0 & 0.5 & 0.0 & 1.6 & 0.0 & 1.1 & 0.0 & 1.0 & 0.0 & 17.5 & 2.4 & 14.0 & 1.0 \\
\hline $40-50 \mathrm{~min}$ & 0.0 & 0.0 & & & 0.0 & 0.0 & 0.1 & 0.0 & 0.1 & 0.0 & 0.0 & 0.0 & 10.0 & 0.9 & 3.0 & 0.0 \\
\hline $50-60 \min$ & 0.0 & 0.0 & 0.0 & 0.0 & 0.0 & 0.0 & 0.0 & 0.0 & 0.0 & 0.0 & 0.0 & 0.0 & 4.0 & 0.3 & 0.0 & 0.0 \\
\hline$>60 \min$ & 0.0 & 0.0 & 0.0 & 0.0 & 0.0 & 0.0 & 0.0 & 0.0 & 0.0 & 0.0 & 0.0 & 0.0 & 0.9 & 0.1 & 0.0 & 0.0 \\
\hline Total & 100 & 100 & 100 & 100 & 100 & 100 & 100 & 100 & 100 & 100 & 100 & 100 & 100 & 100 & 100 & 100 \\
\hline \multicolumn{17}{|c|}{ High Density areas } \\
\hline$<5 \min$ & 83.3 & 99.5 & 73.3 & 98.2 & 46.0 & 90.5 & 61.2 & 87.6 & 34.6 & 83.6 & 23.3 & 63.0 & 13.0 & 55.1 & 13.0 & 52.6 \\
\hline $5-10 \mathrm{~min}$ & 13.1 & 0.4 & 21.3 & 1.7 & 36.6 & 8.2 & 30.1 & 11.7 & 43.0 & 14.2 & 46.9 & 32.3 & 26.7 & 24.2 & 33.8 & 32.1 \\
\hline $10-15 \mathrm{~min}$ & 2.9 & 0.0 & 3.9 & 0.1 & 12.9 & 1.2 & 5.7 & 0.4 & 15.8 & 2.0 & 20.7 & 4.3 & 23.8 & 12.3 & 28.8 & 11.2 \\
\hline $15-20 \mathrm{~min}$ & 0.5 & 0.0 & 1.4 & 0.0 & 3.0 & 0.1 & 2.0 & 0.3 & 4.2 & 0.2 & 5.3 & 0.3 & 17.1 & 5.0 & 16.0 & 3.5 \\
\hline $20-25 \mathrm{~min}$ & 0.0 & 0.0 & & & 1.1 & 0.0 & 0.6 & 0.1 & 1.3 & 0.0 & 2.9 & 0.1 & 11.1 & 2.1 & 5.7 & 0.5 \\
\hline $25-30 \mathrm{~min}$ & 0.0 & 0.0 & & & 0.4 & 0.0 & 0.3 & 0.0 & 0.7 & 0.0 & 0.8 & 0.0 & 5.4 & 1.0 & 1.5 & 0.0 \\
\hline $30-40 \mathrm{~min}$ & 0.0 & 0.0 & 0.1 & 0.0 & 0.0 & 0.0 & 0.1 & 0.0 & 0.3 & 0.0 & 0.1 & 0.0 & 2.7 & 0.3 & 1.0 & 0.0 \\
\hline $40-50 \mathrm{~min}$ & 0.0 & 0.0 & & & 0.0 & 0.0 & 0.0 & 0.0 & 0.0 & 0.0 & 0.0 & 0.0 & 0.1 & 0.0 & 0.0 & 0.0 \\
\hline $50-60 \mathrm{~min}$ & 0.0 & 0.0 & 0.1 & 0.0 & 0.0 & 0.0 & 0.0 & 0.0 & 0.0 & 0.0 & 0.0 & 0.0 & 0.0 & 0.0 & 0.0 & 0.0 \\
\hline$>60 \mathrm{~min}$ & 0.0 & 0.0 & 0.0 & 0.0 & 0.1 & 0.0 & 0.1 & 0.0 & 0.1 & 0.0 & 0.1 & 0.0 & 0.1 & 0.0 & 0.1 & 0.0 \\
\hline Total & 100 & 100 & 100 & 100 & 100 & 100 & 100 & 100 & 100 & 100 & 100 & 100 & 100 & 100 & 100 & 100 \\
\hline \multicolumn{17}{|c|}{ Low density areas } \\
\hline$<5 \min$ & 36.9 & 84.3 & 25.0 & 74.7 & 13.5 & 58.1 & 20.3 & 56.3 & 10.4 & 52.0 & 9.0 & 43.9 & 1.8 & 18.1 & 2.4 & 22.2 \\
\hline $5-10 \min$ & 43.1 & 12.7 & 39.6 & 18.4 & 32.0 & 25.7 & 31.3 & 24.8 & 27.0 & 26.3 & 24.9 & 29.0 & 5.7 & 11.4 & 8.1 & 13.6 \\
\hline $10-15 \mathrm{~min}$ & 15.8 & 2.6 & 23.1 & 5.5 & 28.8 & 10.8 & 22.3 & 9.7 & 27.7 & 12.8 & 28.4 & 16.3 & 10.3 & 16.3 & 14.2 & 18.3 \\
\hline $15-20 \mathrm{~min}$ & 3.5 & 0.4 & 12.2 & 1.4 & 15.8 & 4.0 & 13.3 & 6.3 & 18.9 & 5.7 & 20.2 & 7.4 & 13.2 & 16.4 & 18.4 & 17.8 \\
\hline $20-25 \mathrm{~min}$ & 0.6 & 0.0 & & & 6.7 & 1.1 & 6.7 & 2.1 & 10.3 & 2.4 & 11.5 & 2.6 & 14.0 & 13.7 & 18.4 & 12.9 \\
\hline $25-30 \mathrm{~min}$ & 0.1 & 0.0 & & & 2.5 & 0.2 & 3.9 & 0.5 & 4.1 & 0.6 & 4.5 & 0.6 & 13.3 & 8.8 & 16.7 & 8.1 \\
\hline $30-40 \mathrm{~min}$ & 0.0 & 0.0 & 0.1 & 0.0 & 0.7 & 0.0 & 2.0 & 0.3 & 1.4 & 0.2 & 1.4 & 0.1 & 22.2 & 9.7 & 17.9 & 6.4 \\
\hline $40-50 \mathrm{~min}$ & 0.0 & 0.0 & & & 0.0 & 0.0 & 0.2 & 0.0 & 0.1 & 0.0 & 0.1 & 0.0 & 13.1 & 4.2 & 3.8 & 0.7 \\
\hline $50-60 \mathrm{~min}$ & 0.0 & 0.0 & 0.0 & 0.0 & 0.0 & 0.0 & 0.0 & 0.0 & 0.0 & 0.0 & 0.0 & 0.0 & 5.3 & 1.2 & 0.1 & 0.0 \\
\hline$>60 \mathrm{~min}$ & 0.0 & 0.0 & 0.0 & 0.0 & 0.0 & 0.0 & 0.0 & 0.0 & 0.0 & 0.0 & 0.0 & 0.0 & 1.2 & 0.3 & 0.0 & 0.0 \\
\hline Total & 100 & 100 & 100 & 100 & 100 & 100 & 100 & 100 & 100 & 100 & 100 & 100 & 100 & 100 & 100 & 100 \\
\hline
\end{tabular}




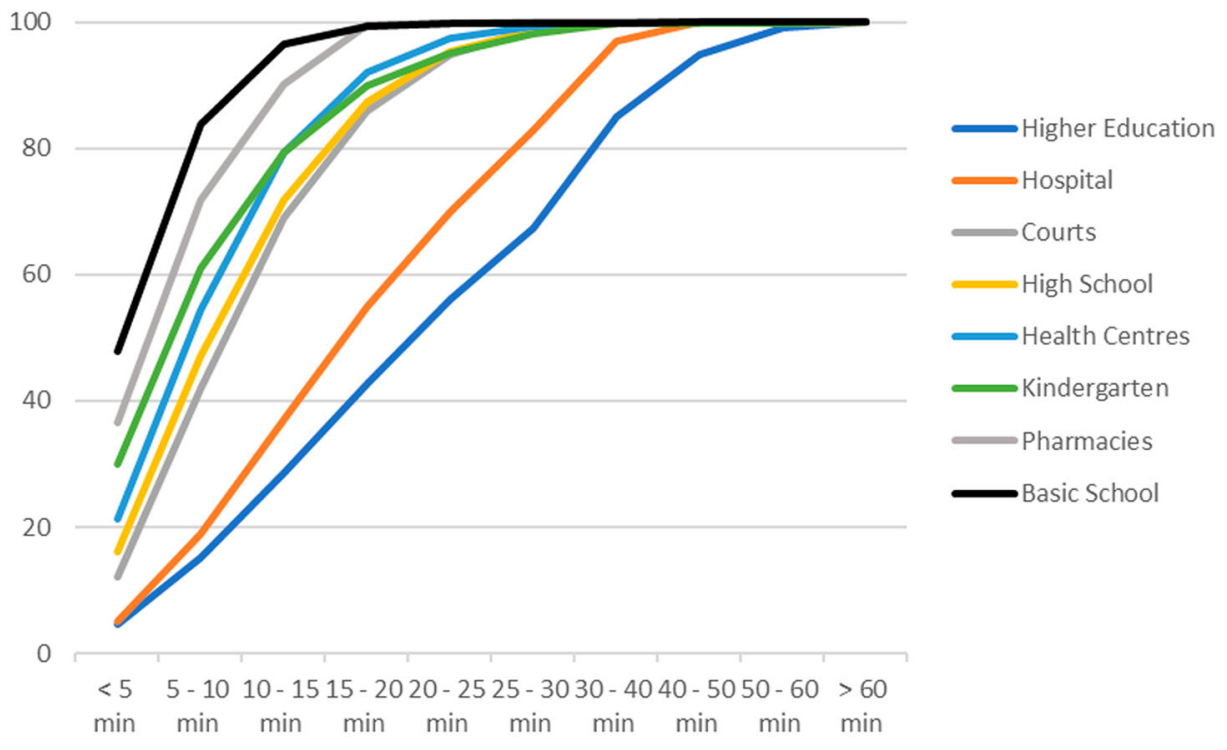

120
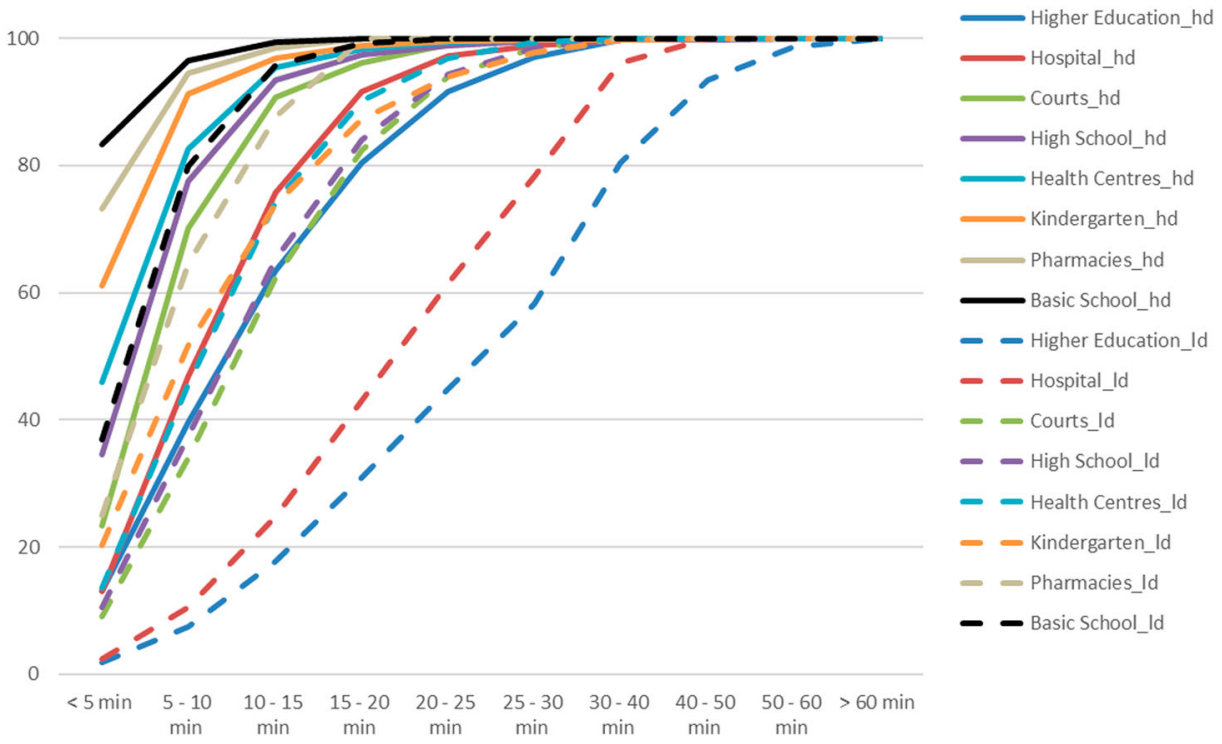

Figure 2. Cumulative percentage of Portugal's area within a given travel time of services of general interest, by the road network; overall (above) and divided by high-density (hd) and low-density (Id) areas (bellow) (source: authors). 

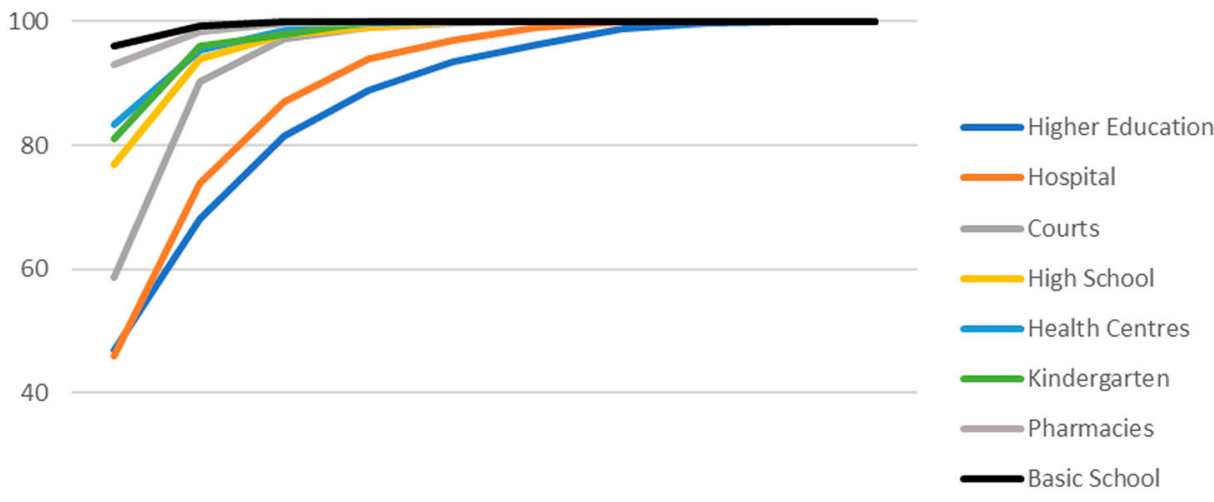

20

0

$<5 \min 5-1010-1515-2020-2525-3030-4040-5050-60>60$ $\min \min \min \min \min \min \min \min \min$

120
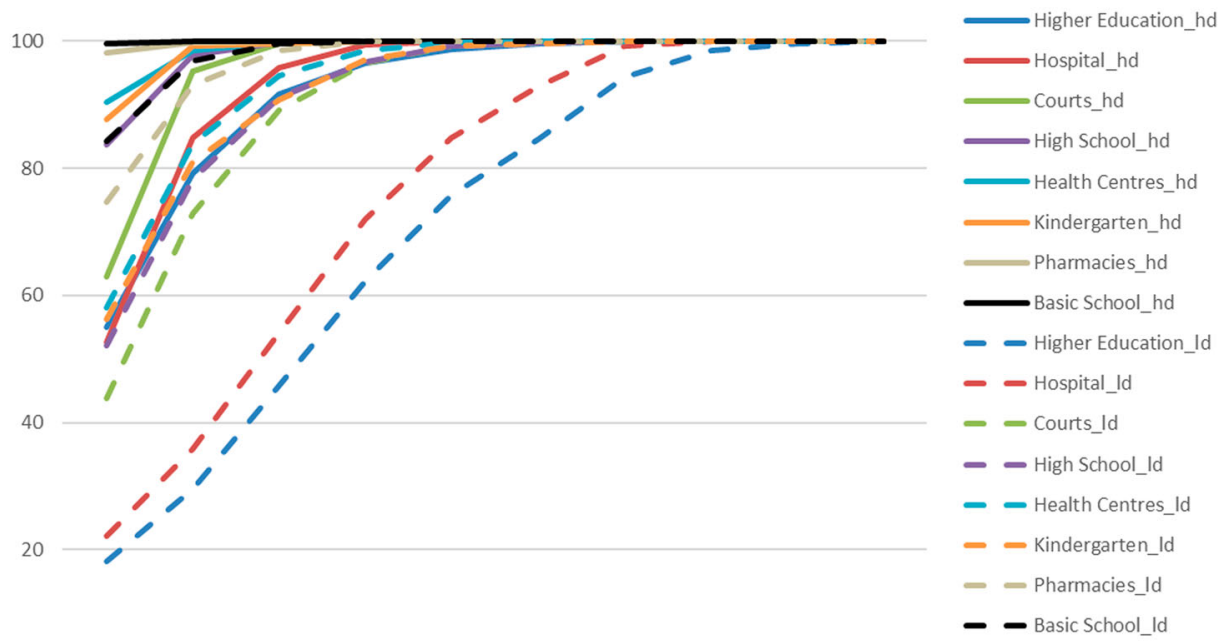

0

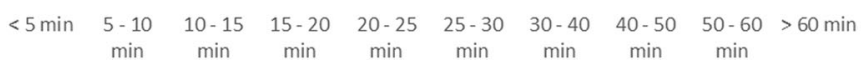

Figure 3. Cumulative percentage of the Portuguese population within a given travel time of services of general interest, by car, overall (above) and divided by high-density (hd) and low-density (Id) areas (bellow) (source: authors).

Figure 4 shows all eight accessibility maps to each service. There is obviously a gradation as we move from low order services, such as Basic Schools and Pharmacies, highly accessible throughout the country, to the high order services. These are particularly 

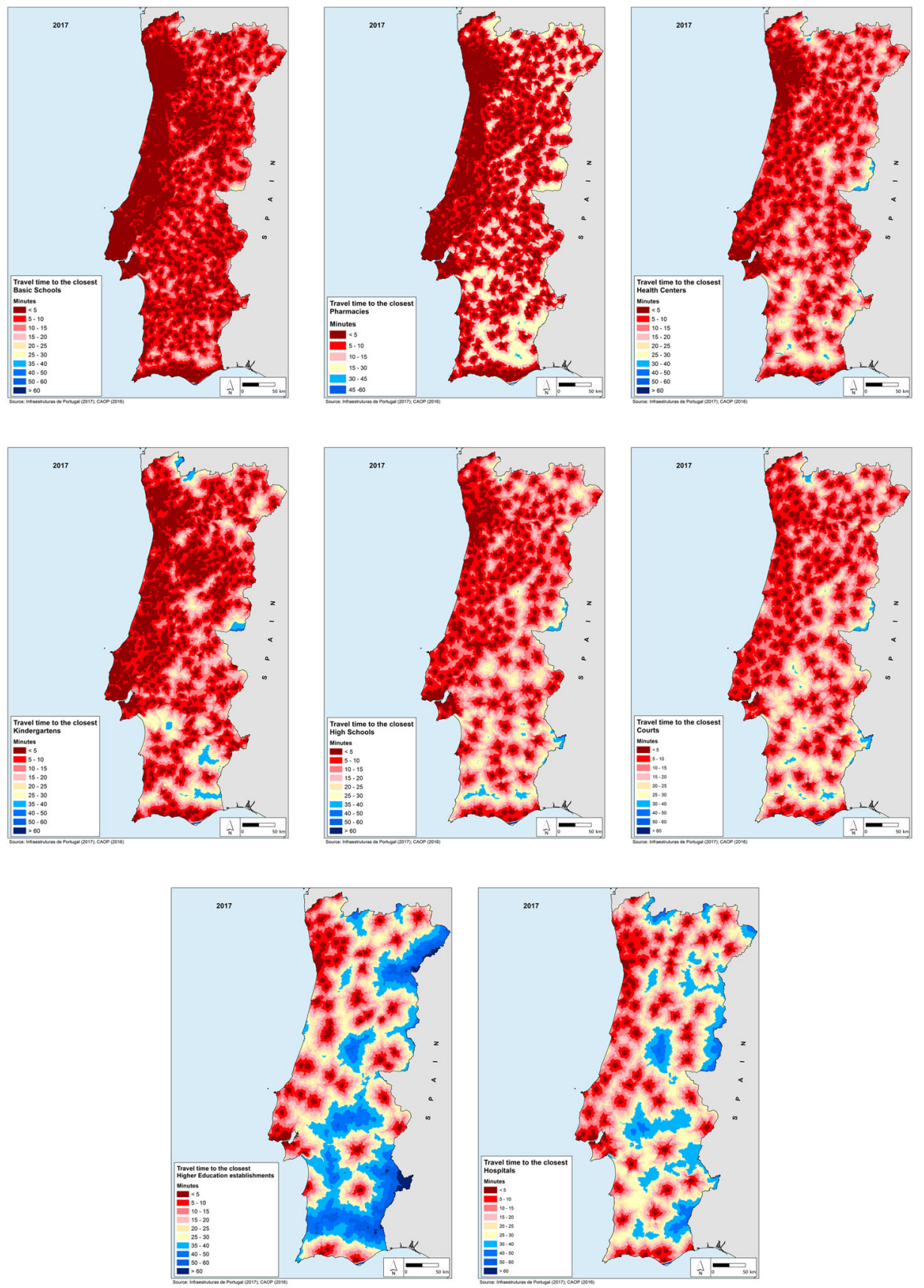

Figure 4. Accessibility to basic services in continental Portugal by different travel times by car (namely Basic Schools, Pharmacies, Health Centres, Kindergartens, High Schools, Courts, Higher Education establishments and Hospitals). 
centred around the metropolitan regions of Lisbon and Porto, the littoral West and South and the main district capitals of the interior. As it can be seen in Table 1 and Figures 2 and 3 , the accessibility to SGI is never actually a problem in the areas of the country with higher population density. The entire population in these areas can immediately access a Basic School and a Pharmacy, and 99\% of the population can reach Kindergartens, Health Centres and High Schools in less than $10 \mathrm{~min}$. Courts can be reached by the entire population in $15 \mathrm{~min}$, and Hospitals and Universities in around $20 \mathrm{~min}$.

This contrasts with the scenario for less developed and less dense regions. The maps in Figure 4 display a particular want in specific regions of the country. Namely, the Southern region of Alentejo, the central Region and near the border with Spain, both to the West and North. In these locations, accessibility to services diminishes considerably. Basic Schools and Pharmacies are only reachable by the entire population at a distance of 15 min by car, with full population access only being guaranteed at 25 min for Courts, High Schools, Kindergartens and Health Centres, and at $50 \mathrm{~min}$ for Higher Education and Hospitals.

This assessment further displays the differences between high and low population density regions of Portugal. Over 95\% of the high-density area has access to Pharmacies and Basic Schools in less than $10 \mathrm{~min}$, but this number is only $80 \%$ for Basic Schools and $65 \%$ for Pharmacies in low-density areas. Courts, High Schools, Kindergartens and Health Centres are accessible for $95 \%$ of the high-density area in $15 \mathrm{~min}$, but only between $60 \%$ and $70 \%$ of the low-density area. And $90 \%$ of the high-density area accesses Higher Education and Hospitals in $25 \mathrm{~min}$, when only half of the low-density area is covered in that travel time, needing another half an hour to cover the remainder.

\subsection{Portugal's overall accessibility score for Services of General Interest}

Combining the eight maps of Figure 4 using Formula (4), the map in Figure 5 can be produced. This map confirms the previous analysis by highlighting as the most accessible regions the corridor in the littoral West, mainly between the larger cities of Lisbon and Porto; the littoral South of the Algarve and notable district capitals of the interior. Low accessibility regions to SGI are primarily in the Centre and South of the country, and along the border with Spain, both on the North and in various locations throughout the East, with particular incidence in the southern region of Alentejo.

Consequently, it can be said that, overall, the littoral and North of the country are better served than the interior and the South. LUISA platform results had previously shown this tendency, but only at regional scale, hence the dichotomy between regional centres with high accessibility and the remaining poorly accessible region had not been perceptible. Furthermore, these results contrast with those obtained by Marques da Costa et al. (2015) in a study at the European scale, in which the Northern regional of Portugal appears in a cluster of lower accessibility to services. However, this data was obtained prior to the opening of a new highway in the interior North. Furthermore, it was obtained through the analyses of variables such as school enrolment, available hospital beds, households with access to broadband or density of motorways, and not by calculating accessibility measures.

In that case, the results of this research do corroborate in part what has been the understanding in the literature of how services of general interest are, and should be distributed, 


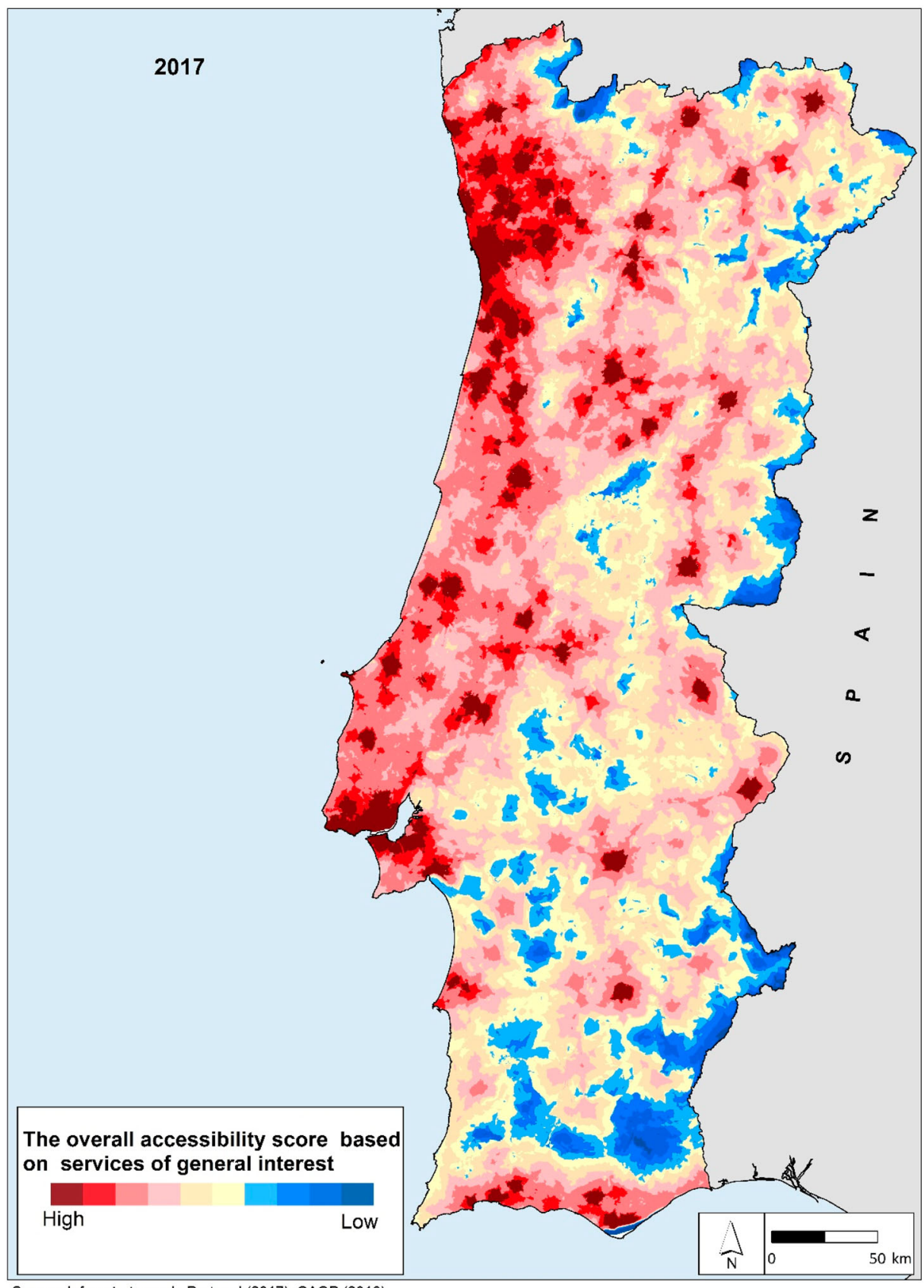

Source: Infraestruturas de Portugal (2017); CAOP (2016)

Figure 5. The overall accessibility score in Portugal based on eight services of general interest.

from Christaller to Milbert et al. (2013). Namely, that low-order centrality services are extensively accessible throughout the territory, unlike high-order centrality level services, whilst middle centrality level services can still cater to some of the population in less dense areas. According to Palma et al. (2015) it can then be assumed that the closer the rural 
areas is to a city or urban area, the more of middle centrality level services will be accessible for the population in this kind of territory. So, polycentricity will have little impact on the low centrality services as they are provided locally, while polycentricity may have a (significant) impact on medium and high centrality services (Palma et al., 2015).

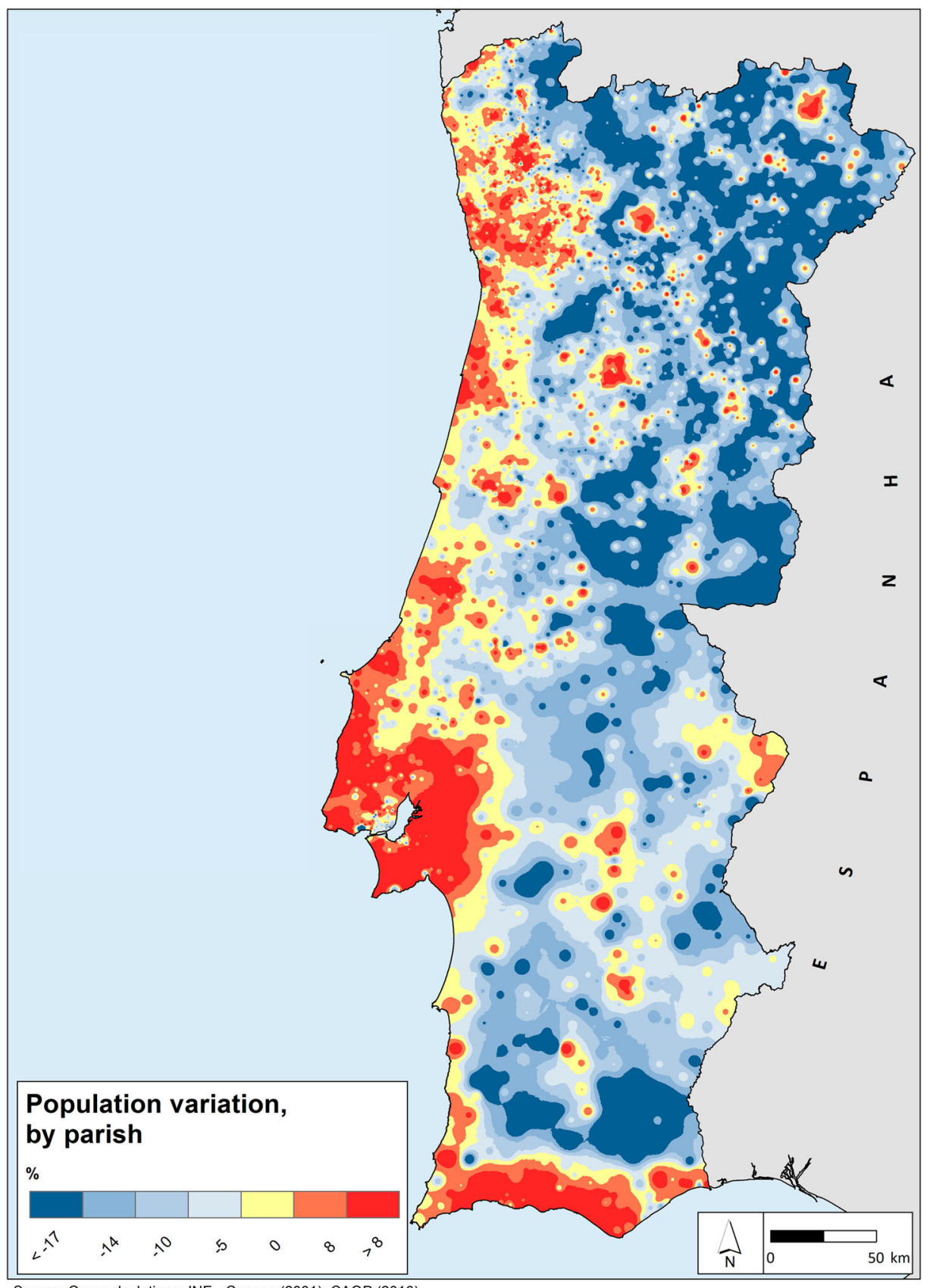

Source: Own calculations; INE - Censos (2001); CAOP (2016)

Figure 6. Variation of the population between 2001 and 2011, by parish, in Portugal. 
In Figure 4 we can find evidence of this by observing that for High Schools and Courts the accessibility is greatest in the littoral and the North, the regions of the country with greater density and more prone to polycentricity. In Figure 5 this polycentric structure is clearly visible, as there are several corridors of high accessibility connecting main cities in the Northern and some Central regions, unlike in the South. However, overall, Portugal does not appear to have so many underprivileged regions as compared to other European regions, which have both a relevant density of population and a low accessibility to SGI (e.g. Milbert et al., 2013). In this case, a good road network and a very concentrated distribution of the population and urban areas results in a high accessibility of the population to services, although there are areas of the country, poorly populated (or which have significantly lost population in the last decades) which have a relatively low accessibility. Figure 6 displays the population variation in Portugal between the last two population census (2001 and 2011). It shows the population loss in the inland regions and the gain in the main urban areas around Lisbon and Porto, in the littoral West, and in the Algarve, to the South. This process of social-spatial divide and demographic and social change has been documented in the Portuguese literature over the decades (Barreto, 1995; Carmo, 2014; Marques, 2003; Nunes, 1964). The country evolved to a spatial structure overlapping three macro-regional spatialities (Ferrão, 2002); a north/south dichotomy, a littoral/interior dichotomy; and a polarizing effect of the medium and major cities (Nunes, Mota, \& Campos, 2011). Thus, it is also noticeable that many of the areas with the lowest accessibility to SGI (shown in Figure 5) coincide with the hotspots of severe population loss.

Consequently, although high density and polycentric regions have the highest levels of accessibility, this does not necessarily mean that there is a great amount of population less served elsewhere in the country, precisely because of the way the urban structure is organized. Only $22 \%$ of the Portuguese population lives in low-density areas, although these encompass $76 \%$ of the territory. And as seen in Table 1, over half of that population can reach the services of general interest of low and medium order in less than 5 min and over two thirds can reach them in under $10 \mathrm{~min}$, whereas around half can reach high order SGI in $15 \mathrm{~min}$. This does not abate the fact, however, that the remaining population in low-density areas, clearly marked in Figures 5 and 6 (around 1 million inhabitants if we consider half the population living in these areas), has indeed a relatively poor accessibility to SGI, particularly of medium and high order, and that these areas are continuing to loose population.

\section{Conclusions}

According to Humer (2014), SGI provision is, on one hand, the outcome of a social welfare policy when it comes to production, financing and assigning them. On the other, it is an outcome of spatial planning policy when it comes to organizing locations, distribution and access to them. To promote equal access, authors like Malý (2016) defend the gradual integration of social and just principles into spatial development policies. However, public service provision and maximum distances allowed are set politically, as Milbert et al. (2013) point out and thus lack theoretical and empirical support. For a well-being modern society, communities require access to various levels of service, but because of isolation and various economic and social constraints, less frequent, high-order services are placed farther from low-density communities. 
In the particular case of Portugal's public policies regarding network infrastructure and accessibility, namely on the context of the new National Plan for Territorial Planning Policies, there has been an effort to reinforce the capacity and usage of public transport, both in urban and rural territories. The purpose has been to increase cohesion and territorial equity through active promotion of public transport, at the same time that different strategies are being implemented to increase the offer of services of general interest. Namely, the paradigm has shifted from a model based on the idea that people travel to reach the service, to a model where the services may 'travel' to the people (for example through the digitalization of public services). This guarantees greater proximity of people to the service, even if this is not a geographical proximity (it is rather a virtual accessibility). However, in the access to services, Portugal remains in many respects the bipolar country many authors had previously described in relation to socio-economic conditions (Barreto, 1995; Ferrão, 2002; Nunes, 1964; Nunes et al., 2011). On the one hand, there is a littoral with high urban and population density, and with high degrees of accessibility to SGI. On the other, a low-density interior, facing more and more the perils of depopulation and ageing. Furthermore, the statistic that in the 2000s Portugal was one of the countries in Europe presenting higher SGI expenditures as shares of the GDP was actually misleading, because it did not represent significant high levels of expenditure per capita (Marques da Costa et al., 2015). On the Cartesian chart presented by Brezzi and Veneri (2015) relating GDP per capita to degrees of polycentricity, Portugal appears on the bottom left half, meaning that it has low levels on both variables.

This does not mean, however, as supported by this research, that there is a significant amount of population without proper access to SGI in Portugal. Unlike other European regions, there are no areas of Portugal where both a relevant density of population and a low accessibility to SGI concur. Also, the amount of population with over 10 or 15 min' access to a basic service is less than one in every ten inhabitants. Nonetheless, this Portuguese paradox is somewhat alarming. Access to SGI is actually improving because the low-density areas (over $70 \%$ of the country's area) are becoming depopulated, as almost $80 \%$ of the country's population lives in high-density areas, with good access to SGI. If this tendency continues to occur, then the accessibility to SGI in Portugal will increase, at least statistically. In fact, irreversible damage may be made to the country's urban system and territorial cohesion. The question is not just whether all the population has a good access to services of general interest. It is whether this access is well distributed across the territory and whether spatial and social injustices that naturally derive from the provision of public services, particularly of medium and higher order, are balanced through careful spatial planning policies. These may be related to the distribution of the services themselves, the creation of more efficient networks of transport, the re-evaluation of the role of certain urban poles within the network, and how they perform within the polycentric model, in articulation with rural or more deprived regions.

Precisely so, polycentricity has been seen as a tool capable of reducing territorial socioeconomic disparities. An analysis such as that performed in this research, at national scale, can give a very important contribution to decision-making in the context of polycentric urban system planning, the cohesion policy agenda and the new National Plan for Territorial Planning Policies in particular. The measurement of accessibility is robust, as it is based on the exact location of services, a comprehensive, up-to-date road network, and the use of simple accessibility measures. The multi-criteria model devised should be the 
object, in subsequent research, of a sensitivity analysis, by considering other services and/ or calculating the overall accessibility values based on levels of services (low, medium, high). This can reveal additional information not surmisable when calculating an overall index where all the service types are considered to have the same weight in the aggregated sum. Areas of low accessibility should be further analysed in terms of socioeconomic conditions, provision of transports and other possible constraints. Finally, it should be noted that the potential to access a service is not a guarantee of actual access. A high order service 20 min away through the road network can just be too far, if there are no possibilities for having, acquiring or boarding a given mode of transport, or if public transport waiting times are greater than the travel time. At the same time, some services such as High Education are not selected by proximity alone; available courses and prestige are important variables in the choices made. Hence, the importance of articulating territorial and spatial planning with other areas of expertise in the cohesion policy debate, and in the access to SGI in particular.

\section{Acknowledgements}

The contribution and support of the Centre of Studies on Geography and Spatial Planning (CEGOT) of the University of Porto for facilitating this research is gratefully acknowledged. We also like to thank the two anonymous reviewers for their insightful comments that helped us improve the final form of this paper.

\section{Disclosure statement}

No potential conflict of interest was reported by the authors.

\section{Funding}

This research, as part of CEGOT, was partially supported by the European Regional Development Fund, through the COMPETE 2020 - Operational Programme 'Competitiveness and Internationalization', under Grant POCI-01-0145-FEDER-006891; and by National Funds through the Portuguese Science and Technology Foundation (FCT) under Grant UID/GEO/04084/2013.

\section{ORCID}

Teresa Sá Marques (D) http://orcid.org/0000-0001-8943-6879

Miguel Saraiva (D) http://orcid.org/0000-0001-5967-661X

Ana Amante (D) http://orcid.org/0000-0003-1718-5323

\section{References}

Alexiadis, S. (2017). Territorial cohesion and prospects for sustainable development: A co-integration analysis. Habitat International, 68, 75-83. doi:10.1016/j.habitatint.2017.03.001

Amante, A. (2017). Medidas de Acessibilidade no Sistema de Planeamento Urbano Português ( $\mathrm{PhD}$ In Civil Engineering - Planning. Faculty of Engineering - University of Porto, Porto.

Apparicio, P., Abdelmajid, M., Riva, M., \& Shearmur, R. (2008). Comparing alternative approaches to measuring the geographical accessibility of urban health services: Distance types and aggregation-error issues. International Journal of Health Geographics, 7(7). doi:10.1186/1476-072x-7-7. 
Apparicio, P., Cloutier, M.-S., \& Shearmur, R. (2007). The case of Montréal's missing food deserts: Evaluation of accessibility to food supermarkets. International Journal of Health Geographics, 6 (4). doi:10.1186/1476-072x-6-4

Baradaran, S., \& Ramjerdi, F. (2001). Performance of accessibility measures in Europe. Journal of Transportation and Statistics, 4(3), 31-48.

Barreto, A. (1995). Portugal na periferia do centro: mudança social, 1960 a 1995. Análise Social, 30 (134), 841-855.

Bertolini, L., le Clercq, F., \& Kapoen, L. (2005). Sustainable accessibility: A conceptual framework to integrate transport and land use plan-making. Two test-applications in the Netherlands and a reflection on the way forward. Transport Policy, 12(3), 207-220. doi:10.1016/j.tranpol.2005.01. 006

Bhat, C., Handy, S., Kckelman, K., Mahmassani, H., Chen, Q., \& Weston, L. (2000). Urban accessibility index: Literature review. Retrieved from https://rosap.ntl.bts.gov/view/dot/14882

Biosca, O., Spiekermann, K., \& Stępniak, M. (2013). Transport accessibility at regional scale. Europa XXI, 24(24), 5-17. doi:10.7163/Eu21.2013.24.1

Borges, L., \& Johansson, M. (2012, August). SGI and territorial structures: European experiences. Bratislava: ERSA Conference.

Brezzi, M., \& Veneri, P. (2015). Assessing polycentric urban systems in the OECD: Country, regional and metropolitan perspectives. European Planning Studies, 23(6), 1128-1145. doi:10. 1080/09654313.2014.905005

Brömmelstroet, M. t., \& Bertolini, L. (2011). The role of transport-related models in urban planning practice. Transport Reviews, 31(2), 139-143. doi:10.1080/01441647.2010.541295

Burger, M. J., \& Meijers, E. (2012). Form follows function? Linking morphological and functional polycentricity. Urban Studies, 49(5), 1127-1149. doi:10.1177/0042098011407095

Burger, M. J., Meijers, E. J., \& van Oort, F. G. (2014). Editorial: The development and functioning of regional urban systems. Regional Studies, 48(12), 1921-1925. doi:10.1080/00343404.2014. 979782

Burger, M. J., van der Knaap, B., \& Wall, R. S. (2014). Polycentricity and the multiplexity of urban networks. European Planning Studies, 22(4), 816-840. doi:10.1080/09654313.2013.771619

Carmo, R. M. (2013). Polycentrism as a multi-scalar relationship between urban and rural areas: The case of Portugal. European Planning Studies, 21(2), 149-166. doi:10.1080/09654313.2012. 722912

Carmo, R. M. (2014). Sociologia dos Territórios: Teorias, Estruturas e Deambulações. Lisboa: Mundos Sociais.

Cattan, N. (2007). Cities and networks in Europe. A critical approach of polycentrism Esher. Surrey: John Libbey Eurotext.

Cerdá, A. (2009). Accessibility: A performance measure for land-use and transportation planning in the Montréal Metropolitan Region (Masters of Urban Planning). McGill University Montreal, Montreal, QC.

Dao, H., Plagnat Cantoreggi, P., \& Rousseaux, V. (2017). Operationalizing a contested concept: Indicators of territorial cohesion. European Planning Studies, 25(4), 638-660. doi:10.1080/ 09654313.2017.1281230

Dühr, S. (2005). Potentials for polycentric development in Europe: The ESPON 1.1.1 project report. Planning Practice \& Research, 20(2), 235-239. doi:10.1080/02697450500414728

EC. (2007). Territorial agenda of the European Union: Towards a more competitive and sustainable Europe of diverse regions. Leipzig: European Commission.

EC. (2011a). A quality framework for services of general interest in Europe. Brussels: European Commission.

EC. (2011b). Territorial agenda of the European Union 2020: Towards an inclusive, smart and sustainable Europe of diverse regions. Gödöllö: European Commission.

El-Geneidy, A., \& Levinson, D. (2006). Access to destinations: Development of accessibility measures. Retrieved from https://conservancy.umn.edu/handle/11299/638

ESPON. (2013). SeGI indicators and perspectives for services of general interest in territorial cohesion and development ESPON applied research 2013/1/16. Final Report \Version, 25(5), 2013. 
ESPON. (2016). Polycentric territorial structures and territorial cooperation. Retrieved from www. espon.eu

ESPON. (2017). PROFECY - processes, features and cycles of inner peripheries in Europe. Interim Report. Retrieved from https://www.espon.eu

EU. (2016). Urban Agenda for the EU; 'Pact of Amsterdam'. Retrieved from https://ec.europa. eu/regional_policy/sources/policy/themes/urban-development/agenda/pact-of-amsterdam. pdf

Evers, D. (2008). Reflections on territorial cohesion and European spatial planning. Tijdschrift Voor Economische En Sociale Geografie, 99(3), 303-315. doi:10.1111/j.1467-9663.2008.00463.x

Faludi, A. (2007). Territorial cohesion and the European model of society. Cambridge, MA: Lincoln Institute of Land Policy.

Fassmann, H., Rauhut, D., da Costa, E. M., \& Humer, A. (2015). Services of general interest and territorial cohesion: European perspectives and national insights. Vienna: Vandenhoeck \& Ruprecht.

Ferrão, J. (2002). Portugal, tres geografias em recombinacao: espacialidades, mapas cognitivos e identidades territorais. Lusotopie, 9(9), 151-158.

Ferrão, J., \& Mourato, J. M. (2010). A avaliação de políticas públicas como factor de aprendizagem, inovação Institucional e cidadania: o caso da política do ordenamento do território em Portugal. Revista Brasileira de Estudos Urbanos e Regionais, 12(1), 9-28. doi:10.22296/2317-1529. 2010v12n1p9

Geurs, K. T., Boon, W., \& Van Wee, B. (2009). Social impacts of transport: Literature review and the state of the practice of transport appraisal in the Netherlands and the United Kingdom. Transport Reviews, 29(1), 69-90. doi:10.1080/01441640802130490

Geurs, K. T., \& van Eck, J. R. (2001). Accessibility measures: Review and applications. Evaluation of accessibility impacts of land-use transportation scenarios, and related social and economic impact. Retrieved from https://rivm.openrepository.com/handle/10029/9487

Geurs, K. T., \& van Wee, B. (2004). Accessibility evaluation of land-use and transport strategies: Review and research directions. Journal of Transport Geography, 12(2), 127-140. doi:10.1016/ j.jtrangeo.2003.10.005

Ginevičius, R. (2008). Normalization of quantities of various dimensions. Journal of Business Economics and Management, 9(1), 79-86. doi:10.3846/1611-1699.2008.9.79-86

Gløersen, E. (2007). Towards an improved understanding of urban profiles and polycentric development potentials: Reflections on ESPON 1.1. 1. In N. Cattan (Ed.), Cities and networks in Europe. A critical approach of polycentrism (pp. 27-37). Esher: John Libbey Eurotext.

Groth, N. B., \& Smidt-Jensen, S. (2007). The ideo-centricity of urban poly-centricity. In N. Cattan (Ed.), Cities and networks in Europe. A critical approach of polycentrism (pp. 81-92). Esher: John Libbey Eurotext.

Hall, P. (2009). The polycentric metropolis: A western European perspective on megacity regions. In J. Xu \& A. G. O. Yeh (Eds.), Governance and planning of mega-city regions: An international comparative perspective (pp. 45-66). New York, NY: Routledge.

Handy, S. L., \& Niemeier, D. A. (1997). Measuring accessibility: An exploration of issues and alternatives. Environment and Planning A: Economy and Space, 29(7), 1175-1194. doi:10. 1068/a291175

Hansen, W. G. (1959). How accessibility shapes land use. Journal of the American Institute of Planners, 25(2), 73-76. doi:10.1080/01944365908978307

Hägerstraand, T. (1970). What about people in regional science? Papers in Regional Science, 24(1), 7-24. doi:10.1111/j.1435-5597.1970.tb01464.x

Hoyler, M., Kloosterman, R. C., \& Sokol, M. (2008). Polycentric puzzles - emerging mega-city regions seen through the lens of advanced producer services. Regional Studies, 42(8), 10551064. doi: $10.1080 / 00343400802389377$

Hull, A., Silva, C., \& Bertolini, L. (2012). Accessibility instruments for planning practice. Porto: COST Office.

Humer, A. (2014). Researching social services of general interest: An analytical framework derived from underlying policy systems. European Spatial Research and Policy, 21(1), 65-82. doi:10.2478/ esrp-2014-0006 
Humer, A., \& Palma, P. (2013). The provision of services of general interest in Europe: Regional indices and types explained by socio-economic and territorial conditions. Europa XXI, 23, 85104. doi:10.7163/Eu21.2013.23.5

Iacono, M., Krizek, K. J., \& El-Geneidy, A. (2010). Measuring non-motorized accessibility: Issues, alternatives, and execution. Journal of Transport Geography, 18(1), 133-140. doi:10.1016/j. jtrangeo.2009.02.002

INE. (2018). Statistics Portugal. Retrieved from www.ine.pt/

Jacobs-Crisioni, C., e Silva, F. B., Lavalle, C., Baranzelli, C., Barbosa, A., \& Castillo, C. P. (2016). Accessibility and territorial cohesion in a case of transport infrastructure improvements with changing population distributions. European Transport Research Review, 8(1), 9. doi:10.1007/ s12544-016-0197-5

Koenig, J. G. (1980). Indicators of urban accessibility: Theory and application. Transportation, 9(2), 145-172. doi:10.1007/BF00167128

Kompil, M., Jacobs-Crisioni, C., Dijkstra, L., \& Lavalle, C. (2019). Mapping accessibility to generic services in Europe: A market-potential based approach. Sustainable Cities and Society, 47, 101372. doi:10.1016/j.scs.2018.11.047

Litman, T. (2003). Measuring transportation: Traffic, mobility and accessibility. Institute of Transportation Engineers. ITE Journal, 73(10), 28.

López, E., Gutiérrez, J., \& Gómez, G. (2008). Measuring regional cohesion effects of large-scale transport infrastructure investments: An accessibility approach. European Planning Studies, 16 (2), 277-301. doi:10.1080/09654310701814629

Makrí, M. B. (2001). Accessibility indices. A tool for comprehensive land-use planning. TLEnet 5th workshop, The Nordic Research Network on Modelling Transport, Nynäshamn, Sweden.

Malý, J. (2016). Questioning territorial cohesion: (Un)equal access to services of general interest. Papers in Regional Science, 0(0). doi:10.1111/pirs.12250

Marques da Costa, E., Palma, P., \& Marques da Costa, N. (2015). Regional disparities of SGI provision. Services of general interest and territorial cohesion (pp. 91-121). Vienna: V\&R Unipress, Vienna University Press.

Marques, T. (2003). Retratos territoriais: Portugal na transição do século (XX/XXI) (PhD thesis). Faculdade de Letras da Universidade do Porto, Porto.

Marques, T. (2016). Sistema Urbano. In J. A. R. Fernandes, L. L. Trigal, \& E. S. Sposito (Eds.), Dicionário de Geografia Aplicada - Terminologia da análise, do planeamento e da gestão do território (pp. 473-475). Porto: Porto Editora.

Medeiros, E. (2016). Territorial cohesion: An EU concept. European Journal of Spatial Development, 60, 1-30.

Milbert, A., Breuer, I. M., Rosik, P., Stepniak, M., \& Velasco, X. (2013). Accessibility of services of general interest in Europe. Romanian Journal of Regional Science, 7, 37-65.

Miller, E. J. (2018). Accessibility: Measurement and application in transportation planning. Transport Reviews, 38(5), 551-555. doi:10.1080/01441647.2018.1492778

Nunes, A. S. (1964). Portugal, sociedade dualista em evolução. Análise Social, 2(7/8), 407-462.

Nunes, G., Mota, I., \& Campos, P. (2011). Policentrismo funcional em Portugal: uma avaliação. FEP Working Paper, 412.

Pain, K. (2007). Integrating the European space: Flows and places in North West European city-region networks. In N. Cattan (Ed.), Cities and networks in Europe: A critical approach to polycentrism (pp. 161-171). Esher: John Libbey Eurotext.

Palma, P., Rauhut, D., \& Humer, A. (2015). Polycentricity and social services of general interest: A multivariate analysis. Paper presented at the 55th Congress of the European Regional Science Association: "World Renaissance: Changing Roles for People and Places", Lisbon, Portugal.

Páez, A., Scott, D. M., \& Morency, C. (2012). Measuring accessibility: Positive and normative implementations of various accessibility indicators. Journal of Transport Geography, 25, 141153. doi:10.1016/j.jtrangeo.2012.03.016

Rauhut, D., \& Ludlow, D. (2013). Services of general interest and territorial cohesion: What, how and by whom? Romanian Journal of Regional Science, 7, 108-123. 
Sadler, R., Gilliland, J., \& Arku, G. (2011). An application of the edge effect in measuring accessibility to multiple food retailer types in southwestern Ontario, Canada. International Journal of Health Geographics, 10(34). doi:10.1186/1476-072x-10-34

Salvati, L., \& De Rosa, S. (2014). 'Hidden polycentrism' or 'subtle dispersion'? Urban growth and long-term sub-centre dynamics in three Mediterranean cities. Land Use Policy, 39, 233-243. doi:10.1016/j.landusepol.2014.02.012

Santinha, G., \& Marques, T. (2012). A integração do princípio de Coesão Territorial na agenda política: o caso português. Revista de Geografia e Ordenamento do Território, 2, 215-244. doi:10.17127/got/2012.2.010

Sánchez-Zamora, P., Gallardo-Cobos, R., \& Romero-Huertas, C. (2017). Assessing the determinants of territorial cohesion: Evidence from Colombian departments. Geoforum; Journal of Physical, Human, and Regional Geosciences, 87, 48-61. doi:10.1016/j.geoforum.2017.10.004

Scheurer, J., \& Curtis, C. (2007). Accessibility measures: Overview and practical applications. Impacts of Transit Led Development in a New Rail Corridor (Working Paper No. 4). Department of Urban and Regional Planning, Curtin University.

Schmitt, P. (2013). Planning for polycentricity in European metropolitan areas - challenges, expectations and practices. Planning Practice \& Research, 28(4), 400-419. doi:10.1080/02697459.2013.780570

Silva, C., Bertolini, L., te Brömmelstroet, M., Milakis, D., \& Papa, E. (2017). Accessibility instruments in planning practice: Bridging the implementation gap. Transport Policy, 53, 135-145. doi:10.1016/j.tranpol.2016.09.006

Silva, C., \& Pinho, P. (2010). The structural accessibility layer (SAL): Revealing how urban structure constrains travel choice. Environment and Planning A, 42(11), 2735-2752. doi:10.1068/a42477

Soja, E. W. (2010). Seeking spatial justice. Minneapolis: University of Minnesota Press.

Stepniak, M., \& Rosik, P. (2016). From improvements in accessibility to the impact on territorial cohesion the spatial approach. Journal of Transport and Land Use, 9(3), 1-13. doi:10.5198/ jtlu. 2015.570

Straatemeier, T., \& Bertolini, L. (2008). Joint accessibility design: Framework developed with practitioners to integrate land use and transport planning in the Netherlands. Transportation Research Record, 2077, 1-8. doi:10.3141/2077-01

Straatemeier, T., Bertolini, L., te Brömmelstroet, M., \& Hoetjes, P. (2010). An experiential approach to research in planning. Environment and Planning B: Planning and Design, 37(4), 578-591. doi:10.1068/b35122

Vale, D. (2010). Sustainable urban form, accessibility and travel: The relationship between polycentric urban development and commuting in Lisbon. Saarbrucken: Lambert Academic.

Vale, D. S., Saraiva, M., \& Pereira, M. (2016). Active accessibility: A review of operational measures of walking and cycling accessibility. Journal of Transport and Land Use, 9(1), 209-235. doi:10. 5198/jtlu.2015.593

Van Wee, B., Geurs, K., \& Chorus, C. (2013). Information, communication, travel behavior and accessibility. Journal of Transport and Land Use, 6(3), 1-16. doi:10.5198/jtlu.v6i3.282

Vandenbulcke, G., Steenberghen, T., \& Thomas, I. (2009). Mapping accessibility in Belgium: A tool for land-use and transport planning? Journal of Transport Geography, 17(1), 39-53. doi:10.1016/ j.jtrangeo.2008.04.008

Vandermotten, C., Halbert, L., Roelandts, M., \& Cornut, P. (2008). European planning and the polycentric consensus: Wishful thinking? Regional Studies, 42(8), 1205-1217. doi:10.1080/ 00343400701874206

Vandermotten, C., Roelandts, M., \& Cornut, P. (2007). European polycentrism: Towards a more efficient and/or more equitable development. In N. Cattan (Ed.), Cities and networks in Europe. A critical approach of polycentrism (pp. 51-62). Esher: John Libbey Eurotext.

Vasconcelos, A. S., \& Farias, T. L. (2012). Evaluation of urban accessibility indicators based on internal and external environmental costs. Transportation Research Part D: Transport and Environment, 17(6), 433-441. doi:10.1016/j.trd.2012.05.004

Zaucha, J., Komornicki, T., Böhme, K., Świątek, D., \& Żuber, P. (2014). Territorial keys for bringing closer the territorial agenda of the EU and Europe 2020. European Planning Studies, 22(2), 246267. doi:10.1080/09654313.2012.722976 